\title{
A RECEPÇÃO DE MACHADO DE ASSIS NOS ESTADOS UNIDOS DURANTE AS DÉCADAS DE 1950 E 1960*
}

\author{
Earl Fitz \\ Vanderbilt University \\ Nashville (TN), Estados Unidos
}

\begin{abstract}
Resumo: Na literatura, a questão da recepção é extremamente complexa e, ao mesmo tempo, essencial, sobretudo se quisermos compreender melhor o impacto que tem em outra uma cultura literária pouco conhecida. Neste artigo, estudo a recepção de Machado de Assis nos Estados Unidos durante os anos 1950, quando três de seus romances - Memórias póstumas de Brás Cubas, Dom Casmurro e Quincas Borba - apareceram pela primeira vez em tradução para o inglês. Também considero a recepção de Machado nos anos 1960, período do chamado "boom", quando o autor brasileiro, apesar de ter sido muito admirado pelo crítico e escritor norte-americano John Barth, não recebeu a aclamação geral que merecia.
\end{abstract}

Palavras-chave: estética da recepção; influência; intertextualidade; boom da literatura hispano-americana.

\section{The reception of Machado de Assis in the United States during the 1950s and 1960s}

\begin{abstract}
This article examines the reception afforded Machado de Assis in the United States during the 1950s and 1960s, the years when Machado was first translated into English and available for reading in the United States and the years of the "Boom" period when he and his texts could have been (but were not) celebrated as part of the generally positive reception given to what was then being called "Latin American" (meaning Spanish American) literature in the United States. The article summarizes how reviewers interpreted Machado's three great novels as they appeared in their generally good English translations (Epitaph of a Small Winner, Dom Casmurro, and Philosopher or Dog?), and how they may have been misinterpreted, by the public and by the critical establishment. The essay also speculates about what might have happened if Machado had been read in the context of some of the great social transformations of the 1950s and 1960s, including questions of race and race relations, gender, class, and economic justice. The article
\end{abstract}

\footnotetext{
${ }^{*}$ Este artigo foi publicado, pela primeira vez, em Luso-Brazilian Review n. 46, v. 1 (2009), p. 16-35. A tradução para o português é de Mariana Magalhães Viana de Barros.
} 
concludes by considering whether the recognition of Brazilian literature in the United States of today would have been greatly enhanced if Machado had received a more emphatically positive reception during the 1950s and 1960s.

Keywords: reader-response theory; influence; intertextuality; Latin American "boom".

As questões interdependentes da influência e da recepção estão entre as mais complexas de toda a literatura. Historicamente, nos estudos comparados, a importância do émetteur, o autor que influencia, ofuscou a do récepteur, o autor influenciado. Entretanto, com o advento da estética da recepção e com a atual velocidade da comunicação internacional, esse paradigma mudou drasticamente, dando-se muito mais atenção à natureza do escritor e da cultura literária que respondem ao estímulo e são influenciados. Por isso, antigas hierarquias literárias estão desmoronando, travam-se diálogos até há pouco inimagináveis, e formam-se novas relações entre diferentes escritores e culturas. Um dos exemplos mais instigantes é o que se poderia chamar de "literatura interamericana", um campo em que o Brasil e seus autores, liderados por Machado de Assis, têm uma atuação de importância crescente.

Quem trabalha com literatura brasileira conhece bem a dinâmica tradicional da influência, já que a maioria de nós passou a carreira lidando com a influência que outros autores, fossem eles da França, da Inglaterra ou dos Estados Unidos, exerceram sobre os brasileiros. No caso de Machado de Assis, por exemplo, já estudamos muito o impacto que tiveram na sua obra pensadores e escritores como Pascal, Sterne, Cervantes, Flaubert, Shakespeare e Dante. No entanto, até agora, tivemos menos oportunidades de estudar a influência que autores brasileiros exerceram sobre escritores de outras culturas e tradições. Meu objetivo neste ensaio é examinar a recepção dada a Machado de Assis nos Estados Unidos durante a década de 1950, quando as traduções da obra de Machado primeiro apareceram em solo norte-americano, e a de 1960, quando a literatura latinoamericana começou a entrar na consciência norte-americana. Para isso, três questões inter-relacionadas devem ser levadas em consideração: (1) o período em questão, o que estava acontecendo nos Estados Unidos dos anos $1950 \mathrm{em}$ termos intelectuais e 
literários; (2) a natureza da arte de Machado, isto é, a natureza dos três romances do autor que, em traduções muito boas, apareceram durante a década de 1950, nesta ordem: Epitaph of a Small Winner (1951; 1952), Dom Casmurro (1953; 1966), e Philosopher or Dog? (1954); ${ }^{1}$ e (3) o relativo "desaparecimento" do Brasil sob a rubrica homogeneizante conhecida como "Boom" latino-americano.

\section{Os Estados Unidos e Machado nos anos 1950}

Na década de 1950, sob o efeito do brilho da vitória aliada sobre a Alemanha nazista e o Japão imperial e entrando no período longo (ainda que não sem interrupções) de prosperidade econômica que perpassaria os anos 1960, os Estados Unidos eram uma cultura pouco interessada na América Latina. Tendo voltado o seu olhar do pós-guerra para a reconstrução da Europa, isto é, para longe do Brasil e da América Hispânica, o país tinha pouco interesse em escritores dissidentes ou que defendessem ideias revolucionárias, fosse em tema ou em forma. Conformidade era a ordem do dia, e os líderes culturais norte-americanos, com poucas vozes discordantes, marchavam no ritmo da unidade e dos objetivos nacionais, os primeiros dos quais eram enrijecer a determinação norte-americana e impedir o crescimento do comunismo internacional. A Guerra da Coreia (1950-1953) e o macartismo (1950-1954), seu equivalente doméstico, apenas solidificaram o propósito norte-americano de unir-se contra a agressão comunista, ao mesmo tempo em que deixaram a população mais receosa de se envolver com o resto do mundo. Ao olhar para além de suas fronteiras, os intelectuais norteamericanos deparavam-se com o que estava em voga: o romance alemão do pós-guerra, o existencialismo francês e os escritos de Sartre e Camus, assim como, um pouco mais para o fim da década, o nouveau roman. E, pertinente à questão aqui discutida, também houve a ascensão de um novo e estonteante senso do "excepcionalismo" norte-

\footnotetext{
${ }^{1}$ Publicada em São Paulo, a primeira tradução de Memórias póstumas de Brás Cubas (The posthumous memoirs of Brás Cubas) para o inglês, feita por William Grossman, apareceu em 1951. Quando o mesmo texto surgiu nos Estados Unidos, no ano seguinte, 1952, mudou-se o título para Epitaph of a small winner ["Epitáfio de um pequeno vencedor"], que é como ficou conhecido até 1997, quando, em uma nova tradução, Gregory Rabassa recuperou o título original em inglês. Dom Casmurro, traduzido por Helen Caldwell, foi publicado na Inglaterra em 1953. No entanto, só foi editado nos Estados Unidos em 1966, talvez para tentar beneficiar-se da popularidade da literatura latinoamericana na época do Boom. Em 1954, Quincas Borba foi traduzido para o inglês por Clotilde Wilson, com o título de Philosopher or $\operatorname{dog}$ ?
} 
americano, impulsionado pela saída dos Estados Unidos da Guerra como uma potência internacional. Em 1946, apesar do alto preço que pagou em termos de vidas perdidas e afetadas, o país emergiu da Segunda Guerra Mundial com a sua estrutura social, sua indústria de base e seu sistema econômico intactos e prontos para se expandirem. Com base no que haviam realizado na Guerra, os norte-americanos, ao se olharem no espelho, achavam que podiam ser perdoados por tudo, viam o seu próprio sucesso, achavam que o seu jeito era o jeito certo de agir e que deviam acreditar nele sem questionar coisa alguma. Essa postura logo se tornaria problemática para os Estados Unidos, marcados por contradições, tensões e problemas internos sérios; e ao mesmo tempo essa postura também tendia a isolar os americanos do resto do mundo e, pior ainda, exacerbar seu provincianismo e sua xenofobia, muitas vezes levando o país a agir de forma arrogante e a desconsiderar as outras culturas e suas realizações - um problema que, em certo grau, ainda nos assola mesmo em 2008.

Sintomático do Zeitgeist cultural anticomunista dos Estados Unidos no início da década de 1950 foi o resultado de um grande simpósio patrocinado pela Partisan Review em 1952. Este simpósio se deu em plena Guerra da Coreia e na era de McCarthy, além de ocorrer um ano depois de os "Estudos americanos" se estabelecerem como uma nova disciplina acadêmica nas universidades e faculdades da nação. Os participantes procuraram avaliar o que se acreditava ser uma relação nova e mais simbiótica entre os artistas, escritores e intelectuais norte-americanos e o status social, político e econômico do país no mundo da Guerra Fria. "Será que os intelectuais norteamericanos agora veem os Estados Unidos e suas instituições de uma nova forma", perguntavam os organizadores, e será que eles "se sentem mais próximos do seu país e da sua cultura?". ${ }^{2}$ A conclusão, apesar da opinião de alguns céticos (como Norman Mailer, por exemplo, cujo artigo nesse número de Partisan Review está nas páginas 298-301), foi que a intelligentsia do país estava intimamente alinhada com os conceitos prevalecentes do que significava ser "americano". Enquanto, em gerações anteriores, os escritores e pensadores dos Estados Unidos tinham receio de abraçar muitos dos seus valores mais dúbios (o caráter filisteu, por exemplo, ou as hipocrisias sociais e

\footnotetext{
2 Partisan Review. PHILLIPS, William; RAHV, Philip (Orgs.). Our country and our culture: a symposium. v. 19, n. 3 (mai.-jun. 1952.), p. 282.
} 
políticas), em 1952, com os temores de um "totalitarismo russo"³ e da aniquilação nuclear, eles assumiram uma posição bem mais protetora e até mais simpatizante em relação às posições políticas, políticas econômicas e tendências culturais norteamericanas. O que se acreditava serem valores americanos determinantes eram então menos alvos de críticas do que os problemas da "cultura de massa" e do "boosterism" (a autopromoção) que ela parecia exigir. ${ }^{4}$ Se frequentemente ainda éramos um país de "Babbitts"5 e "provincianos", como afirma Lionel Trilling na mesma revista (p. 323), nós o éramos consideravelmente menos após a experiência internacionalizante da Guerra do que havíamos sido no início do século. ${ }^{6}$ Apenas os escritores do movimento "beat" resistiram de forma sistemática a essa adesão pouco crítica ao "sonho americano", embora, conforme Alfred Kazin apontara dez anos antes em On native grounds (Em solo nativo), ${ }^{7}$ os autores norte-americanos historicamente tenham tendido a absorver "cada detalhe do seu mundo norte-americano", ao mesmo tempo em que expressavam "sua profunda e sutil alienação em relação a ele". Para Kazin, os romancistas do país mapearam esse senso de distanciamento não em termos puramente teóricos, mas "em solo nativo", ${ }^{8}$ que é onde, com uma visão mais abrangente do hemisfério, poderiam ter identificado uma causa comum em um escritor como Machado de Assis, que, como veremos, tinha muito a oferecer aos norte-americanos nesse particular. Mas essa conexão nunca foi feita, e, assim, enquanto a época de Eisenhower (1953-1961) se caracterizou por uma crença nas corporações, na conformidade e no American way, as melhores obras de escritores como Saul Bellow, Flannery O'Connor, Allen Ginsberg e Ralph Ellison confirmavam a afirmação de Kazin, mas de uma forma que continuava a levar os norte-americanos a olharem para o interior, para a sua própria situação, e não para o exterior, para o resto do mundo. Entre 1945 e 1960, cada vez mais

\footnotetext{
${ }^{3}$ Idem, p. 284.

${ }^{4}$ Idem, p. 284-285.

${ }^{5}$ Ver Sinclair Lewis, Babbitt [1922]. A história do protagonista, um negociante de cidade pequena, é um estudo sobre como a mentalidade burguesa americana não só é conformista, como também tirânica.

${ }^{6}$ Nas palavras de Lionel Trilling, escrevendo em 1952: "Pela primeira vez na história do intelectual americano moderno, os Estados Unidos não devem ser concebidos, a priori, como a nação mais vulgar e idiota do mundo" (Partisan Review, cit., p. 319).

${ }^{7}$ KAZIN, Alfred. On native grounds: an interpretation of modern American prose literature. Nova Iorque: Reynal \& Hitchcock, 1942.

${ }^{8}$ Idem, p. ix.
} 
as forças sociais, políticas e culturais que impulsionavam o país eram centrípetas, e não centrífugas. $^{9}$

Considerando-se esse ambiente intelectual muito satisfeito consigo mesmo e extremamente autocentrado, como, então, os críticos americanos reagiram a Memórias póstumas de Brás Cubas quando da primeira publicação da tradução do romance em 1952? Como reagiram a um texto que era - e ainda é - tão desafiador em tantos níveis e sentidos e que vinha de uma cultura literária que tendiam a descartar, se é que chegavam a pensar nela? Numa das suas primeiras entrevistas, S. M. Fitzgerald escreve que um "niilismo barato"10 desfigura o romance e diminui o seu valor. Anthony West, escrevendo para a New Yorker em agosto de 1952, tem mais coisas positivas a dizer, embora discuta o livro, de forma revoltante, como um clássico menor. ${ }^{11}$ Harvey Curtis Webster, ao escrever para a New York Times Book Review em 1953, salienta o papel que a ambiguidade representa na ficção machadiana e menciona a introdução de Waldo Frank, muito perceptiva, que, se tivesse sido reimpressa em outras edições das obras de Machado, certamente teria provocado um efeito positivo na sua recepção. ${ }^{12}$ Entretanto, talvez o mais intrigante dos primeiros críticos tenha sido Dudley Fitts, que, ao escrever em 13 de julho de 1952 na New York Times Book Review, apontou a necessidade de mais "compreensão interamericana"13 e sugeriu que a aparição tardia de Machado de Assis em inglês finalmente começaria a intensificar a presença do Brasil nos Estados Unidos. Fitts também é autor de outra das mais importantes resenhas iniciais de Machado, resenha em que consegue simultaneamente declarar Machado um "grande" escritor, merecedor de mais reconhecimento, ${ }^{14}$ e descrever a sua obra em termos que o tornariam anátema para um público norte-americano carola e autocomplacente. Ao escrever, por exemplo, que "Nenhum satirista, nem mesmo Swift, é menos misericordioso" que Machado de Assis "em sua exposição da pretensão e da hipocrisia

\footnotetext{
${ }^{9}$ MCQUADE, Donald; ATWAN, Robert; BANTA, Martha; KAPLAN, Justin; MINTER, David; TICHI, Cecilia; VENDLER, Helen (Orgs.). The Harper American Literature. v. 2. Nova Iorque: Harper and Row, 1987. p. 1754.

${ }^{10}$ FITZGERALD, S. M. A belated discovery. New Republic, 15 set. 1952, p. 20.

${ }^{11}$ WEST, Anthony. A minor classic. New Yorker, 9 ago. 1952, p. 71.

${ }^{12}$ WEBSTER, Harvey Curtis. A short life is not bitter... Saturday Review 35, 26 jul. 1952, p. 9.

${ }^{13}$ FITTS, Dudley. A masterpiece from Brazil. New York Times, 13 jul. 1952, p. 4.

${ }^{14}$ Idem, p. 19.
} 
subjacentes na média das boas pessoas", Fitts acrescenta que "Machado, com seu jeito enganosamente afável, é assustador". ${ }^{15}$ Quando aponta, também, o que acredita ser o "pessimismo" de Machado, que ele diz que "se aproxima do niilismo", ${ }^{16}$ Fitts deixa o seu leitor norte-americano de 1954 face a face com os problemas interdependentes da malaise moderna, a "decadência espiritual"17 e a decadência cultural, nenhum dos quais teria sido particularmente palatável para o público da era de Eisenhower. Sem ser explícito, James Stern traz essa questão mais para perto da realidade norte-americana quando escreve, também em 1954, sobre o suposto cinismo de Machado (em oposição ao cinismo dos seus personagens) e sobre como a sua obra disseca o caráter raso da "burguesia brasileira do século XIX"18 e as vidas superficiais e inautênticas que levam enquanto procuram ostentar suas fortunas e macaquear a moda europeia. William Grossman, um dos primeiros e mais habilidosos tradutores de Machado, põe como que um ponto de exclamação nessa linha de pensamento ao afirmar, numa matéria de 1954 da Saturday Review, que o leitor americano teria dificuldade de penetrar a ironia de Quincas Borba e que o romance "o recompensaria com uma chicotada onde mais dói, ou seja, nas suas premissas". ${ }^{19}$ Esta observação sobre o livro atinge com violência os valores da classe média e nos mostra mais uma vez por que, para a maioria dos norteamericanos no início dos anos 1950, Machado teria sido um escritor que talvez viessem a admirar por sua inventividade técnica, mas cuja crítica implícita à própria cultura deles nunca abraçariam.

No entanto, de modo geral, parece-me correto concluir que Memórias póstumas de Brás Cubas, Dom Casmurro e Quincas Borba - e, portanto, o próprio Machado - obtiveram uma cautelosa reação positiva da crítica americana, descontadas algumas leituras míopes. ${ }^{20}$ Também acredito, entretanto, que os resenhistas não perceberam os aspectos mais importantes desses romances (ou a eles deram pouca

\footnotetext{
${ }^{15}$ FITTS, Dudley. Legacy from Brazil. New Republic 131, 20 set. 1954, p. 19.

${ }^{16}$ Idem, p. 20

${ }^{17}$ Ibidem.

${ }^{18}$ STERN, James. Illusion of grandeur. New York Times Book Review, 18 jul. 1954, p. 19.

${ }^{19}$ GROSSMAN, William L. Victory and potatoes. Saturday Review 37, 17 jul. 1954, p. 12.

${ }^{20} \mathrm{Na}$ edição de 6 de junho de 1953 da New Yorker, por exemplo, o crítico anônimo "Briefly Noted" descreveu Dom Casmurro como levando o leitor "à impaciência em vez da compaixão, pois a centelha de vida que se esconde atrás dele é tão remota e [...] tão fraca" (p.136).
} 
importância): o manejo do tempo narrativo, da metáfora e da colagem; os experimentos com o que se chamaria mais tarde de "metaficção"; a criação de narradoresprotagonistas autoconscientes que podem ou não ser não confiáveis; a criação de um novo leitor, não mais passivo; o uso da ironia e as críticas sutis aos danos causados pela obediência cega ao egoísmo - o próprio princípio em que se baseava, nos anos 1950, a América das grandes corporações. Em suma, os Estados Unidos dos anos 1950 não ofereciam um ambiente intelectual convidativo à voz amarga e desiludida de Machado de Assis, e isso pode ter prejudicado a sua recepção.

Ao se analisarem as primeiras reações, parece que, ao mesmo tempo em que os críticos americanos acharam Memórias póstumas interessante e curioso, passaram ao largo da sua verdadeira genialidade. Isso se deu, acredito, porque eles não esperavam encontrar tanta sutileza e sofisticação em um escritor de quem nunca tinham ouvido falar, proveniente de um lugar, o Brasil, a que não associavam a literatura de alta qualidade, ao contrário de países como França, Alemanha, Inglaterra e Rússia. O rico e diversificado patrimônio literário brasileiro, epítome da différance no Novo Mundo, era completamente negligenciado e desvalorizado. Mais que isso, as contínuas relações feitas entre o romance de Machado e Laurence Sterne e seu Tristram Shandy tiveram o efeito de relegar as Memórias póstumas à condição de mera imitação de um texto celebrado da tradição novelística inglesa e, com isso, descartá-lo como inerentemente inferior. Ao não se darem o trabalho de comparar com atenção os dois textos e de considerar a possibilidade de a obra de Machado ir além da de Sterne, em termos do espalhafato temático e estrutural, e de, ao fim e ao cabo, fazer pelo romance moderno algo semelhante ao que Baudelaire fez pela poesia moderna, os críticos americanos fecharam os olhos para as características mais extraordinárias do livro. Em 1952, por exemplo, H. C. Webster declara que Machado "imita Sterne de forma demasiadamente servil", ${ }^{21}$ e outros críticos sugerem o mesmo.

Apenas Dudley Fitts, em seu texto publicado em 1954 na New Republic, chega a sugerir que o autor brasileiro pode ter superado Sterne, atingindo maior profundidade psicológica $^{22}$ e fazendo com que sintamos a terrível vacuidade de uma vida baseada no

\footnotetext{
${ }^{21}$ WEBSTER, Harvey Curtis. A short life is not bitter..., cit., p. 9.

${ }^{22}$ FITTS, Dudley. Legacy from Brazil, cit., p. 20.
} 
egoísmo, no materialismo, na exploração e em um desejo de possuir tanto objetos quanto pessoas. Um pressuposto comum nos estudos da influência - e que parece ter influído de forma negativa na opinião dos críticos americanos de Machado - é que o texto influenciado é quase sempre inferior ao texto que influencia (o que explica por que a mera caça às fontes tantas vezes se revela uma tarefa ociosa). No entanto, o caso de Memórias póstumas de Brás Cubas e sua relação com Tristram Shandy mostra a falácia desse pressuposto, e uma atenta leitura comparativa dos dois demonstra de forma dramática por que o texto brasileiro é superior, intelectual e esteticamente, ao do escritor irlandês. Produto de uma formação rigidamente eurocêntrica e prejudicados por uma falta de exposição à história e à cultura da América Latina (ou, pior ainda, incapacitados por um desdém por ela), os críticos americanos não conseguiram reconhecer a originalidade e o poder do suave (mesmo nas suas primeiras traduções) e cômico, mas profundamente iconoclástico, Machado de Assis. Caso contrário, a recepção de Machado nos Estados Unidos certamente teria sido diferente.

\section{Machado e os anos do "Boom"}

Graças aos trabalhos recentes de Piers Armstrong, ${ }^{23}$ Irene Rostagno, ${ }^{24}$ Johnny Payne, ${ }^{25}$ Deborah $\mathrm{Cohn}^{26}$, Sophia A. McClennen ${ }^{27}$ e outros, estamos começando a entender melhor o que aconteceu durante esse importante período, embora seja verdade que a história completa do papel nele desempenhado pela literatura brasileira ainda carece de um exame mais aprofundado. Todos sabemos que o próprio termo "Boom" é equivocado, já que apenas mostra quão pouco a cultura norte-americana sabia sobre a literatura da América Hispânica e do Brasil (ou com ela se importava), onde brilhantes e

\footnotetext{
${ }^{23}$ ARMSTRONG, Piers. Third world literary fortunes: Brazilian culture and its international reception. Lewisburg: Bucknell University Press, 1999.

${ }^{24}$ ROSTAGNO, Irene. Searching for recognition: the promotion of Latin American literature in the United States. Westport, CT: Greenwood Press, 1997.

${ }^{25}$ PAYNE, Johnny. Conquest of the New Word: experimental fiction and translation in the Americas. Austin: The University of Texas Press, 1993.

${ }^{26} \mathrm{COHN}$, Deborah. History and memory in the two souths: recent Southern and Spanish American fiction. Nashville: Vanderbilt University Press, 1999.

${ }^{27}$ MCCLENNEN, Sophia A. Comparative Literature and Latin American Studies: from disarticulation to dialogue. In: MCCLENNEN, Sophia A.; FITZ, Earl E. (Orgs.). Comparative Cultural Studies and Latin America. West Lafayette: Purdue University Press, 2004.
} 
sofisticadas obras em prosa de ficção, poesia e teatro vinham sendo escritas desde 1492 e 1500, respectivamente. Em 1964, por exemplo, um livro amplamente disseminado, On contemporary literature ("Sobre a literatura contemporânea"), organizado por Richard Kostelanetz, continha estudos sobre as literaturas norte-americana, francesa, alemã, espanhola (mas não portuguesa) e britânica, e sobre escritores como Saul Bellow, Albert Camus, Alain Robbe-Grillet, Eugène Ionesco e Isaac Bashevis Singer, mas não oferecia nada sobre literatura latino-americana moderna. Até a literatura canadense (ao menos a variante anglófona) foi abordada. Foi apenas em sua segunda edição, publicada em $1969,{ }^{28}$ que a obra moderou seus devaneios europeus e mencionou um escritor da América Latina, Borges, com o "estudo" não sendo senão o ensaio já muito discutido de John Barth, "The literature of exhaustion" ("A literatura da exaustão"). Mesmo no fim dos anos 1960, nem todos os estudiosos e críticos norte-americanos estavam interessados em literatura latino-americana ou em conceder-lhe um assento à mesa da literatura mundial.

Entretanto, como uma espécie de contrapeso a esse sentimento excludente, surgiu outro livro importante também em 1969, The TriQuarterly anthology of contemporary Latin American literature ("Antologia trimestral de literatura latinoamericana contemporânea"). ${ }^{29}$ Com o romancista chileno José Donoso e William Henkin servindo de organizadores, essa coletânea de ficção, poesia e crítica era atípica, pois continha escritores da América Hispânica e do Brasil. No entanto, Machado de Assis não estava entre eles, tendo feito sua estreia americana no início dos anos 1950 cedo demais para ser notado por não brasilianistas, mesmo no fim da década de 1960, quando os Estados Unidos estavam finalmente começando a tomar consciência cultural dos seus vizinhos de hemisfério mais ao Sul. Àquela época, obviamente, os estudantes de literatura latino-americana moderna sabiam que os escritores emblemáticos do "Boom" não representavam o nascimento da literatura da América Hispânica e nem mesmo seu aparecimento súbito, mas sim a consequência lógica de experimentos

\footnotetext{
${ }^{28}$ KOSTELANETZ, Richard (Org.). On contemporary literature. Expanded edition. Nova Iorque: Avon, 1969.

${ }^{29}$ DONOSO, José; HENKIN, William (Orgs.). The TriQuarterly anthology of contemporary Latin American literature. Nova Iorque: E. P. Dutton, 1969.
} 
narrativos que, na América Hispânica, haviam começado na década de $1940^{30}$ e, no Brasil, nas décadas de 1930 e 1920 - e mesmo antes, a se considerar o Machado de Assis pós-1880. Como Emir Rodríguez Monegal observa em 1969, de seu posto em Yale, "com lentidão exasperante, os efeitos do Boom na nova literatura latino-americana estão começando a ser sentidos mesmo aqui nos Estados Unidos". "Afinal", continua Monegal usando Edmund Wilson e Lionel Trilling como referência,

[...] este é um país no qual, até recentemente, os melhores críticos se recusaram sistematicamente a levar a sério qualquer novo livro latinoamericano [...] Então, é de se espantar, em um país onde críticos importantes revelam preconceitos assim, que a maioria veja a América Latina apenas como um continente distante, de revoluções e de fome? [...] Portanto, os efeitos do Boom ainda precisam se fazer sentir [e] a luta contra o preconceito literário cego [precisa continuar]. ${ }^{31}$

Uma queixa semelhante é expressa por John Brushwood, que, em 1987, escreve, sobre seus concidadãos americanos vergonhosamente insulares:

[...] nossa resistência à literatura estrangeira envolve mais que a América Latina. Somos um povo extremamente provinciano, a despeito das vidas e do dinheiro que espalhamos pelo globo. Nós resistimos à literatura estrangeira em geral, e essa posição básica é exacerbada quando se trata de países que não são poderosos financeira ou militarmente. ${ }^{32}$

Mas se, como a maioria dos brasilianistas, partirmos do pressuposto de que o "Boom" ficou quase imediatamente identificado apenas à América Hispânica, e não ao Brasil, ${ }^{33}$ então nosso problema tem na verdade dois desdobramentos: (1) como era a

\footnotetext{
${ }^{30}$ Ver, por exemplo: BRUSHWOOD, John. Two views of the Boom: North and South. Latin American Literary Review, Special issue: "The Boom in retrospect: a reconsideration". Yvette E. Miller and Raymond Leslie Williams, editors, v. 25, n. 29 (jan.-jun. 1987), p. 24.

${ }^{31}$ MONEGAL, Emir Rodríguez. The new Latin American Literature in the USA. Review 68. Nova Iorque: The Center for Inter-American Relations, 1968, p. 3.

${ }^{32}$ BRUSHWOOD, John. Two views of the Boom: North and South, cit., p. 14.

${ }^{33}$ Ver também MERQUIOR, José Guilherme. The Brazilian and Spanish American literary traditions: a contrastive view. In: GONZÁLEZ, Roberto González; PUPO-WALKER, Enrique (Orgs.). The Cambridge History of Latin American Literature. v. 3. Cambridge: Cambridge University Press, 1996. p. 379-380.
} 
literatura brasileira que estava sendo traduzida para o inglês na época (ou, no caso de Machado, que já havia sido traduzida), em comparação aos textos da América Hispânica então sendo vertidos para o inglês?; (2) como os críticos americanos reagiram a ela, em comparação com a reação aos textos da América Hispânica aos quais estavam começando a ter acesso? No que diz respeito à primeira parte da questão, é útil lembrar que, para os Estados Unidos, o início da década de 1960 foi marcado de forma indelével pelos efeitos residuais da desastrosa viagem realizada em 1958 pelo então vicepresidente Richard Nixon à América Latina. Esta, após ser usada durante a Guerra para fins estratégicos e explorada por causa de suas matérias-primas essenciais para o esforço de guerra, fora abruptamente abandonada por Washington, ao fim do conflito, em favor da Europa. Ainda mais importantes para as relações entre a América do Norte e a do Sul durante a década foram o sucesso da Revolução Cubana de Fidel Castro, entre 1959 e 1960, e a crise dos mísseis de Cuba, em outubro de 1962, acontecimentos que levaram os norte-americanos a pensar na América Latina de forma distorcida e a identificá-la apenas à América Hispânica. Embora o então presidente do Brasil constitucionalmente empossado, João Goulart (que tinha sido o vice-presidente de Jânio Quadros, o qual renunciara em 1961), tivesse sido deposto em 1964 com o apoio do governo norteamericano, foram a Revolução Cubana, o fracasso da baía dos Porcos e a crise dos mísseis de Cuba - todos tão próximos da costa norte-americana - que prenderam a atenção dos escritores, artistas e intelectuais do país durante os anos 1960. O Brasil, apesar de inquestionavelmente mais importante em termos estratégicos para os interesses a longo prazo dos Estados Unidos, foi deixado de lado, enquanto a parte hispanófona da América Latina passou para primeiro plano, fortalecida, é preciso dizer, por uma pletora de excelentes escritores e intelectuais, bem como por uma profusão de líderes políticos carismáticos e astutos.

Como evidencia seu importantíssimo ensaio de 1969, "The new Latin American literature in the USA" ("A nova literatura latino-americana nos EUA"), até mesmo Monegal tende a minimizar, ou até a elidir, a singularidade cultural do Brasil, ao mencionar apenas um escritor brasileiro, Guimarães Rosa (cuja coletânea de histórias The third bank of the river é rapidamente discutida), e, ainda assim, simplesmente incluindo-o em meio a autores mais conhecidos da América Hispânica, tais como 
Borges, Fuentes, Cortázar, García Márquez, Onetti e Neruda. ${ }^{34}$ Embora Monegal conhecesse muito bem a literatura brasileira e, em outros veículos, a houvesse elogiado e comparado de forma muito positiva com a sua irmã da América Hispânica, nesse caso (em um ensaio no geral totalmente louvável, que foi lido por muitos autores, críticos e estudantes americanos), ele pouco se esforça para distinguir da América Hispânica o Brasil, seus escritores ou suas tradições. Da perspectiva de um leitor norte-americano, o resultado é que - em uma conjuntura essencial em termos da recepção da literatura latino-americana nos Estados Unidos - um verdadeiro especialista estava (inadvertidamente, é de se presumir) transmitindo a impressão errônea de que havia pouca ou nenhuma diferença entre o brasileiro, Guimarães Rosa, e seus equivalentes "latino-americanos" mais celebrados. Nenhuma menção a Clarice Lispector ou Machado de Assis, que Monegal reconhecera anteriormente em seu livro, ou a Jorge Amado, que havia sido recebido de forma calorosa pelo público leitor americano, tornando-se enfim um best-seller. De qualquer forma, a partir de 1960, a América Latina se torna, na cabeça da maioria dos americanos, sinônimo de nações como Cuba, Nicarágua, Guatemala, Venezuela, Colômbia, México e Argentina. O Brasil, gigantesco e lusófono, tão diferente da América Hispânica em termos de tradições históricas, culturais e literárias, se tornou praticamente "invisível" aos olhos americanos, como os americanos afrodescendentes nos Estados Unidos, no retrato feito por Ralph Ellison em 1952, com seu romance Invisible man (O homem invisível). Apesar dos esforços da família Rockefeller, de Orson Welles (cujo filme "É tudo verdade" causara um escândalo em Hollywood), da Política da Boa Vizinhança de Roosevelt e da Aliança para o Progresso de Kennedy, o Brasil - e a cultura brasileira em especial praticamente desapareceu do radar americano dos anos 1960. As duas exceções notáveis seriam a Bossa Nova, que gozou de um grande sucesso nos Estados Unidos da época, e Gabriela, cravo e canela, de 1958 (traduzida como Gabriela, clove and cinnamon, em 1962), de Jorge Amado, romance amplamente lido no país, que parecia corroborar ideias norte-americanas a respeito do "progresso" e da tecnologia, ao mesmo tempo em que se encaixava em estereótipos norte-americanos envolvendo sol, praia e sexo "latinos". Para os brasilianistas interessados na recepção da literatura brasileira no país, é uma fonte de frustração permanente o fato de que é Jorge Amado (inegavelmente um

\footnotetext{
${ }^{34}$ MONEGAL, Emir Rodríguez. The new Latin American Literature in the USA, cit., p. 3, 4 e 8.
} 
excelente contador de histórias), e não Machado de Assis (ou Clarice Lispector ou Guimarães Rosa), o escritor brasileiro que os americanos tendem a conhecer, pelo menos de nome, o escritor que, mesmo em meados dos anos 1980, é escolhido para "representar" a literatura sul-americana no país. ${ }^{35}$

No que diz respeito à segunda parte dessa questão, igualmente importante, a maneira com que a crítica americana oficial reagiu à descoberta da literatura latinoamericana no início dos anos 1960, é preciso recorrer rapidamente à história literária. Como Johnny Payne aponta em Conquest of the New Word: experimental fiction and translation in the Americas (A conquista da Nova Palavra: ficção experimental e tradução nas Américas), ${ }^{36}$ mais ou menos no período entre 1952 e 1967, os críticos americanos estavam abismados com o que julgavam ser o estado aparentemente deplorável da ficção americana, sua "prostração", sua "confusão" e seu senso de isolamento. ${ }^{37}$ Stephen Koch, por exemplo, ao escrever em 1967, sentia-se vexado o bastante para declarar que "nos últimos quinze anos, a literatura em inglês chegou ao fundo do poço e sobreviveu ao que na [sua] opinião será visto como o ponto mais baixo e empobrecido da sua história desde 1870". ${ }^{38}$ Essa afirmação fez eco a uma declaração já feita pelo famoso romancista Philip Roth, que, em 1961, sentiu ser necessário dizer:

[...] o escritor americano em meados do século XX está ocupado em tentar entender, e depois descrever, e depois tornar crível boa parte da realidade americana. Esta desconcerta, enoja, enfurece e, por fim, é até mesmo uma espécie de embaraço para a esquálida imaginação do autor. A realidade continuamente supera nossos talentos, e a cultura

\footnotetext{
${ }^{35}$ Por exemplo, Amado é o único autor brasileiro mencionado por José Donoso em seu Historia personal del Boom e é o único brasileiro incluído entre autores "latino-americanos" tais como Borges, Vargas Llosa, Cortázar e García Márquez, a quem em 1984 se atribuiu o mérito de transformar as letras latinoamericanas em "uma importante corrente em meio à principal" da literatura mundial (WILKIE, Brian; HURT, James [Orgs.]. Literature of the Western World. 1. ed. Nova Iorque: Macmillan Publishing Company, 1984. v. 2. p. 2078). Amado também é o único brasileiro a quem, em 1987, os editores de The Harper American Literature, v. 2, apontam como tendo ajudado a "internacionalizar" as letras americanas.

${ }^{36}$ PAYNE, Johnny. Conquest of the New Word: experimental fiction and translation in the Americas. Austin: The University of Texas Press, 1993. No original, há um trocadilho entre "New Word" (nova palavra) e "New World" (novo mundo), que se perde na tradução. [N.T.]

37 Ver: VIDAL, Gore. Ladders to Heaven. In: KOSTELANETZ, Richard (Org.). On contemporary literature. Expanded edition. Nova Iorque: Avon, 1969. p. 29-30.

${ }^{38} \mathrm{KOCH}$, Stephen. Premature speculations on the perpetual Renaissance. TriQuarterly Review, 10. Fall 1967, p. 4-19. A citação é da página 5.
} 
cria com uma frequência quase diária figuras que causam inveja a qualquer romancista [...] Os jornais diários [...] nos enchem de assombro e admiração - e desespero. Isso está realmente acontecendo? E, é claro, de nojo e desespero. Os impasses, os escândalos, as insanidades, as traições, as idiotices, as mentiras, as hipocrisias, o ruído $[\ldots]^{39}$

Com o argumento de que os "leitores americanos" abraçaram de forma entusiástica o que acreditavam ser a "tropicalidade" e o exotismo da ficção "latino-americana", considerando-a como um antídoto para o problema descrito acima, vindo esses leitores rapidamente a apropriá-la "como uma 'solução' para uma crise de autoconfiança específica na sociedade e na ficção americanas contemporâneas", Payne acredita que, para os escritores americanos, "uma infusão do trópico afastou o entrópico". ${ }^{40} \mathrm{Se}$ aceitarmos a tese de Payne, ela seria válida para um escritor hispano-americano como Alejo Carpentier, Miguel Ángel Asturias ou García Márquez, mas não se aplicaria ao brasileiro Machado de Assis, que deve ser visto como um dos escritores menos "tropicais" que se poderia encontrar. Mais uma vez, o Brasil se perde no caldeirão latino-americano. Como veremos, a ironia disso é que, caso os críticos e escritores americanos tivessem dado mais atenção a Machado e aos seus três romances então disponíveis (conhecidos por algumas pessoas influentes), eles teriam encontrado um modelo artístico e intelectual muito superior no qual basear sua própria regeneração literária.

E assim permanece a questão decisiva e desconcertante: por que Machado, cujos grandes romances - Memórias póstumas de Brás Cubas, Dom Casmurro e Quincas Borba - foram publicados nos Estados Unidos pela primeira vez na primeira metade da década de 1950 e angariaram reações relativamente positivas da crítica, não foi (e ainda hoje não é) sequer mencionado como um dos escritores do Boom? Como explicar esse descuido grosseiro, essa omissão gritante? A resposta, acredito, tem dois aspectos: um deles envolve o escritor americano John Barth e o outro, mais complicado, envolve o que David Jackson descreve como o talento de Machado para representar "as anomalias da alienação, da perversão, da dominação, da crueldade e da loucura", e a

\footnotetext{
${ }^{39}$ ROTH, Philip. Writing American fiction. In: KLEIN, Marcus (Org.). The American novel since World War II. Nova Iorque: Fawcett, 1969. p. 144-145.

${ }^{40}$ PAYNE, Johnny. Conquest of the New Word: experimental fiction and translation in the Americas, cit., p. 8,4 e 15 .
} 
sutil habilidade do escritor brasileiro de "desconstruir o império", ao mesmo tempo em que cultiva um cômico "estilo autoconsciente de descontinuidade, fragmentação e inovação gráfica [...]", empregando "estratégias de deslocamento que exploram a diferença entre a voz autoral e a visão acentuadamente restrita dos narradores masculinos". ${ }^{41}$ Ao retornar nas suas narrativas pós-1878 à tradição cervantina e ao explorar a forma do romance como artifício verbal, como "ilusão, jogo, ambiguidade e aventura", ${ }^{42}$ Machado é simultaneamente arcaico e moderno. Sempre apresentando uma afável subversão em suas explorações do lado negro da psicologia humana e em suas dissecções da alienação e das hipocrisias culturais, e exigindo um leitor novo após 1880, mais envolvido e com mais discernimento, Machado, empregando a ironia e a paródia, "proclama a sua modernidade como escritor". ${ }^{43}$

Ao comparar a modernidade de Machado à de Gogol e Tchekhov, J. G. Merquior parece concordar com Jackson, assinalando que Machado "exibe tanto um apetite pela linguagem quanto um gosto pela desintegração moral e pelo chiaroscuro que são totalmente modernos - com efeito, bem mais modernos que o seu contemporâneo norte-americano Henry James". ${ }^{44}$ Embora seja razoável imaginar que algumas dessas características - em especial o uso da ironia - teriam sido atraentes para os críticos americanos dos anos 1950, período no qual o New Criticism, centrado no texto, ainda dominava, a maior parte dos outros aspectos do gênio de Machado (o uso hábil da paródia, as experimentações com diversas formas do narrador não confiável, o "gosto pela degradação moral" e, acima de tudo, a inclinação a revelar a "perversão, [...] a crueldade e a loucura" da elite socialmente dominante) não o seria. Com a violência da Segunda Guerra Mundial ainda fresca na memória coletiva e diante do que seria considerado como um inimigo implacável durante a Guerra Fria, os Estados Unidos do início da década de 1950 não eram uma cultura que ansiasse por ter suas fraquezas expostas, muito menos por um escritor praticamente desconhecido, proveniente de uma nação mais associada a Carmen Miranda do que a uma grande literatura. Apesar de

\footnotetext{
${ }^{41}$ JACKSON, K. David. Madness in a tropical manner. The New York Times Book Review, 22 fev. 1998, Nova Iorque, p. 15.

42 Idem.

${ }^{43}$ Idem.

${ }^{44}$ MERQUIOR, José Guilherme. The Brazilian and Spanish American literary traditions: a contrastive view, cit., p. 369.
} 
Machado ter sido reconhecido na América Latina como um precursor autêntico e de valor inestimável da "nueva novela latinoamericana", ${ }^{45}$ ainda não foi recebido como um dos grandes romancistas americanos, ou do Novo Mundo, o que certamente mudará com o desenvolvimento do campo da literatura interamericana. Como professores e estudiosos, uma das nossas tarefas deve ser provocar essa mudança o mais rápido possível.

Teria sido Machado um "grande anacronismo", como já foi sugerido, um escritor extraordinariamente talentoso que, por uma série de razões, estava apenas na hora e no lugar errados, destinado a um longo período de incompreensão por ser tão profético em relação aos temas e tão à frente do seu tempo em termos de técnica? Acredito que isso seja bastante possível, e seria uma forma legítima de se pensar a recepção do escritor nos Estados Unidos dos anos 1950 e 1960. Indo contra a mentalidade materialista do "homem [branco] do terno de flanela cinza" e contra o conformismo da época, alguns autores americanos estavam nos estágios iniciais da dissenção e, como o escritor brasileiro setenta anos antes, começavam a questionar a moral do capitalismo e a natureza de uma sociedade baseada na escravidão e na hipocrisia. Um dos traços distintivos da literatura produzida no país nos anos posteriores à Segunda Guerra Mundial - traço que, mais uma vez, poderia ter ligado Machado à experiência norte-americana - é o fato de que autores sulistas, judeus e negros começaram a explorar os diversos conflitos e preconceitos que definiam a identidade étnica, social e econômica dos Estados Unidos da época. Por que - pode-se perguntar o Machado dos anos 1950 não foi invocado em apoio a essas lutas? Uma vez que havia abordado tão reveladoramente esses problemas em Memórias póstumas de Brás Cubas, por que não foi reconhecido como um escritor que questionava a moral de uma cultura baseada na escravidão, na opressão e na busca de satisfação de desejos e interesses individuais? Por que não foi lido nos Estados Unidos como um autor que tinha algo importante a dizer sobre relações raciais, como evidenciam Prudêncio (de Memórias Póstumas) e, em Quincas Borba, o escravo doméstico negro, que precisa se esconder atrás da porta enquanto a Casa Grande é administrada por criados brancos importados da Europa? Em Gênio, seu livro de 2002, por exemplo, Harold Bloom descreve

\footnotetext{
45 MONEGAL, Emir Rodríguez. El Boom de la novela latinoamericana. Caracas: Editorial Tiempo Nuevo, 1972. p. 53-54.
} 
Machado como "o maior literato negro surgido até o presente". ${ }^{46}$ Embora, como defende M. L. Nunes, o objetivo de Machado fosse obter reconhecimento como artista, como escritor, e não como um escritor "negro, branco ou mulato", ${ }^{47}$ é possível imaginar como ele teria sido recebido nos Estados Unidos da década de 1950 ou nos anos 1960, tão turbulentos em termos raciais, se tivesse sido visto como proveniente de uma cultura que tinha muito a ensinar aos americanos na questão racial - para não falar em questões de justiça social e econômica, nos efeitos da pobreza, nos conflitos de classe e no status da mulher. Como teria sido a recepção de Machado nos Estados Unidos se tivesse sido apresentado no mercado de forma diferente ou se tivesse sido imediatamente reconhecido pelos críticos como um escritor que tinha algo importante a dizer sobre as grandes questões da época? As respostas a essas perguntas estão sem dúvida relacionadas à sutileza e à sofisticação das técnicas do Machado romancista, mas, para os brasilianistas, que têm um longo histórico de comparar seus escritores aos de outros países, tais conexões parecem tão óbvias quanto naturais.

Entretanto, para que os críticos norte-americanos tivessem lido Machado dessa maneira culturalmente mais relevante, teria sido necessário que tivessem uma noção muito mais positiva do que realmente tinham do valor daquilo que um escritor "latinoamericano" poderia fazer. Se Machado tivesse sido traduzido do francês ou do alemão, como um representante dessas tradições literárias mais respeitadas, acredito que teria obtido uma recepção muito mais entusiástica; com efeito, estou certo de que ele teria sido louvado como o verdadeiro mestre moderno que de fato foi. $\mathrm{O}$ escritor, podemos concluir, foi duplamente amaldiçoado: por vir da tradição literária latino-americana, que, para a maioria - se não para todos - dos leitores e críticos americanos dos anos 1950 e 1960 (e até da década de 1980), era pouco mais que "remotas paragens da literatura mundial"; ${ }^{48}$ e por ser do Brasil, país tão marginalizado pelos americanos a ponto de se tornar invisível mesmo no contexto da América Latina. Esse tipo de preconceito literário e cultural profundamente arraigado é muito difícil de superar,

\footnotetext{
${ }^{46}$ BLOOM, Harold. Joaquim Maria Machado de Assis. In: da história da literatura. Rio de Janeiro: Objetiva, 2003. p. 687. Gênio: os 100 autores mais criativos

${ }^{47}$ NUNES, Maria Luísa. The craft of an absolute winner: characterization and narratology in the novels of Machado de Assis. Westport, CT: Greenwood Press, 1983.

${ }^{48}$ WILKIE, Brian; HURT, James (Orgs.). Literature of the Western World. v. 2. Nova Iorque: Macmillan Publishing Company, 1984. p. 2078.
} 
mesmo por críticos geralmente justos e abertos, e inquestionavelmente prejudicou a recepção inicial do escritor nos Estados Unidos.

A questão da ligação de Barth com Machado de Assis também chama a atenção, tornando-se, afinal, talvez, o fator decisivo em termos do que aconteceu com Machado durante os anos do Boom. Embora de forma bem menos veemente que Koch, Barth, ao escrever para a revista Atlantic apenas alguns meses mais tarde, em agosto de 1967, também mostra preocupação com o que acredita ser a "sensível exaustão" da ficção americana, o senso de "esgotamento de determinadas formas"49 que lhe pareciam permeá-la e prejudicá-la. O ensaio de Barth "A literatura da exaustão" foi amplamente lido e alcançou grande influência, e, apesar de não ser evidente à época, pode ser visto hoje, em retrospecto, como um grande facilitador da recepção da literatura latinoamericana no país. Na verdade, não é exagero ver na inteligente obra de Barth um marco fundamental nas relações interamericanas, a primeira vez em que, de uma maneira séria e substancial, um escritor e crítico americano de peso celebrou publicamente um escritor latino-americano, Borges, e chegou até mesmo a defender que esse autor latino-americano poderia ser visto pelos americanos como a solução para a sua "crise de autoconfiança".

Para os brasilianistas, hoje e naquela época, o que mais decepciona nessa declaração fundamental de Barth sobre a excelência da literatura latino-americana é que em nenhum momento do ensaio ele menciona Machado de Assis, um escritor que conhecia e admirava desde que o descobriu por acaso em meados dos anos 1950; um escritor que ele generosamente reconhece como a influência primária para o seu primeiro romance publicado, A ópera flutuante, de 1956, e também para o seu desenvolvimento como escritor em início de carreira. ${ }^{50}$ A resposta, para parafrasear (livremente) a visão de Brás Cubas, tem a ver simplesmente (nada mais sinistro do que isso) com um mau timing, pois em futebol, na vida e nos estudos da recepção, timing é tudo. O próprio Barth insinua isso quando discute o desenvolvimento natural da sua relação com Machado e quando ele próprio evolui, de um escritor inexperiente, em

\footnotetext{
${ }^{49}$ BARTH, John. The literature of exhaustion. In: The friday book. Nova Iorque: G. P. Putnam's Sons, 1984. p. 64.

50 _. Further fridays: essays, lectures, and other nonfiction, 1984-94. Nova Iorque: Little, Brown and Company, 1995. p. 44-45; 165-167; 290.
} 
busca de soluções para problemas técnicos que ainda não havia conseguido resolver, ${ }^{51}$ para um escritor que amadurecia rapidamente, um escritor de gosto cosmopolita e interesses cambiantes. Tendo "perdido seu dente de leite com os grandes modernistas", afirma Barth:

\begin{abstract}
Deparei-me com a obra de ficção de Machado de Assis, escritor brasileiro do fim do século XIX [...] e houve um estalo. Ao menos na tradução americana, esses romances pareciam ter acabado de ser escritos. Não tínhamos o termo "pós-modernismo" em nosso vocabulário crítico nos anos 1950, mas a combinação que Machado fazia de malabarismos formais, autoconsciência e autorreflexão narrativa, pessimismo político e seriedade emocional temperada com comédia seca - esses elementos formavam uma espécie de proto-pósmodernismo que realmente me atraiu muito. Meu primeiro romance, $A$ ópera flutuante, foi escrito sob a influência benigna de Joaquim Machado de Assis. ${ }^{52}$
\end{abstract}

Mas, como revela Barth, quando A ópera flutuante foi publicado, em 1956, seu autor já havia começado a "virar as costas" para "o realismo e o minimalismo" e - no mesmo movimento, presume-se - para "a influência benigna" de Machado, voltando-se para "as extravagâncias altamente energéticas de The sot weed factor e sua espécie de irmão gêmeo, Giles goat-boy". ${ }^{53}$ Foi durante esse período de crescimento artístico - ou transição artística - que Barth descobriu Borges, ${ }^{54}$ instante em que "ficou sem fôlego" pela segunda vez (Machado foi a primeira) diante de um escritor latino-americano inovador e inspirador. "No momento em que me deparei com as Ficções de Borges pela primeira vez", escreve, "tive a sensação desorientadora mas familiar de que tudo devia parar até que eu tivesse assimilado aquele escritor extraordinário", sendo o ensaio "A literatura da exaustão" uma tentativa de "realizar essa assimilação". ${ }^{55}$ Portanto, entre 1956 e 1966, ano em que Giles goat-boy foi publicado, a influência de Borges sobre Barth era crescente, enquanto a de Machado, minguante. $O$ resultado desse

\footnotetext{
${ }^{51}$ Idem, p. 44-45; 257-258

52 Idem, p. 44.

${ }^{53}$ BARTH, John. Further fridays: essays, lectures, and other nonfiction, 1984-94, cit., p. 259.

54 _. The literature of exhaustion, cit, p. 63.

55 _. Further fridays: essays, lectures, and other nonfiction, 1984-94, cit., p. 45.
} 
enfraquecimento, ao que parece, é que, apesar de ainda ser um "favorito" de Barth, ${ }^{56}$ Machado de Assis estava suficientemente fora dos seus pensamentos em 1967 para não aparecer em "A literatura da exaustão". Como sabemos, esse famoso ensaio é todo louvores a Borges, o escritor da América Latina que seria o estopim da recepção do Boom nos Estados Unidos, e que John Updike já havia visto em 1965 como uma possível "escapatória do beco sem saída do narcisismo e do lixo da ficção americana atual". ${ }^{57}$ De modo interessante, Updike chega a mencionar Machado e seu "ceticismo absoluto" nesse ensaio, ${ }^{58}$ mas não discute o escritor nem as suas muitas inovações técnicas, nem o compara a Borges, o que ele poderia ter feito no que diz respeito à ligação entre a linguagem e a realidade que a linguagem se propõe a representar, e entre a relação de autor, texto, personagens e narradores com o leitor. Em vez de discutir qualquer desses temas, Updike se volta para Borges e declara que suas "ficções" respondem a "uma profunda necessidade na arte literária contemporânea: a necessidade de confessar a existência do artifício",59 que, tendo início com a troça de Brás Cubas "Ao leitor" e terminando com o discurso metaficcional trágico de Dom Casmurro, é exatamente o que, embora de forma menos óbvia que Borges, Machado havia feito entre 1880 e 1908, ano de sua morte.

Mas, deixando Updike de lado, e se Barth tivesse discutido Machado no seu ensaio de 1967? Que diferença teria feito, se é que haveria diferença, em termos da recepção do autor nos Estados Unidos e - o que é ainda mais intrigante - em termos de como o Boom se desenvolveria no país, talvez de maneira mais vantajosa para o Brasil e os seus escritores? Antes de chegar a uma conclusão, talvez valesse a pena especular um pouco sobre essas questões. Para começar, é importante lembrar que a preocupação de Barth em "A literatura da exaustão" não era o tema, mas sim a forma. Não surpreende, pois, que Barth fosse golpeado pela "nova narrativa" de Borges; o surpreendente é que ele aparentemente não percebeu a natureza revolucionária do "novo romance" de Machado, romance este que, já em Memórias póstumas de Brás Cubas, exemplificava um tipo de forma narrativa radicalmente nova, no qual um texto solapa o próprio senso

\footnotetext{
${ }^{56}$ Idem, p. 290.

${ }^{57}$ UPDIKE, John. The author as librarian. The New Yorker, 30 out. 1965, p. 223-246.

${ }^{58}$ Idem, p. 236.

${ }^{59}$ Idem, p. 246.
} 
de estabilidade e sentido que suas palavras parecem apresentar e que - bastante evidente no caso de Machado - vê a necessidade urgente de criar um novo tipo de leitor para si, mais atento e judicioso. Se Borges, festejado pelos críticos franceses nos anos 1950, era o autor estruturalista por excelência, Machado, ativo mais ou menos cinquenta anos antes, pode facilmente ser considerado o primeiro autor pós-estruturalista, o primeiro ficcionista na tradição ocidental a deliberadamente borrar a velha distinção entre linguagem e metalinguagem - ou seja, entre ficção e crítica - e a perceber que o romance não é uma representação da realidade (mimese) exata ou mesmo necessariamente "fiel", mas um construto puramente verbal, um artifício cujo significado permeia seu próprio estatuto de sistema semiótico fechado e se modifica dependendo da maneira com que o leitor reorganiza ou reconsidera diferentes capítulos, cenas e discursos. Como Saussure um pouco mais tarde, Machado entendeu já em 1880 que o sentido na linguagem e, portanto, na literatura é tanto relativo à diferença quanto uma função dela, e que na linguagem e, portanto, na literatura, não há termos necessariamente positivos para impedir que essas diferenças estejam em permanente jogo semântico. O sentido, então, torna-se fluido e instável, dependente da reação do leitor ao texto. Esta é a essência da famosa ambiguidade de Machado, que pode ser muito mais bem compreendida em termos de pensamento pós-estruturalista do que em termos de pós-modernismo, o termo crítico que Barth usaria mais tarde para descrever Machado, termo que muito possivelmente o induziu em erro quanto às experimentações romanescas mais importantes do autor. Quando Barth, imerso na tradição narrativa anglo-americana, escreveu que estava preocupado com o "esgotamento" de algumas formas, ele se referia ao realismo e à sua tradicional confiança no que se supunha ser a ligação íntima e vital entre a palavra e o objeto, entre a linguagem e a realidade - e especialmente a realidade tridimensional. Se é isso o que Barth tinha em mente quando escreveu "A literatura da exaustão", então é fácil compreender quão encantado ele teria ficado pelas mágicas "ficções" fantásticas de Borges e sua desconcertante demonstração de que uma ficção imaginativa e instigante não precisava estar atada a qualquer realidade exterior a ela mesma, e que, na verdade, essa ficção poderia funcionar perfeitamente bem como seu próprio sistema semiótico autossuficiente. 
Mas se, antes de escrever seu ensaio seminal, Barth se tivesse voltado ao passado e relido Machado, ${ }^{60}$ talvez tivesse percebido que o mestre brasileiro já havia modificado a natureza da forma do romance e que, como aponta David Haberly, ele o havia feito ao alterar e até ignorar "as regras básicas do realismo europeu do século XIX", por meio da experimentação com o que seus críticos posteriores chamariam de "antirromance" e do cultivo de uma série de narradores cativantes e narradoresprotagonistas, cuja "não confiabilidade evidente" ao mesmo tempo nos encanta e nos engana, levando-nos finalmente a confrontar não a realidade bem organizada do realismo, mas - o que é muito mais perturbador - "a realidade fundamentalmente impossível de se conhecer" das nossas vidas e da existência humana. ${ }^{61}$ Já em 1880, 83 anos antes de René Wellek fazer a mesma afirmação e cerca de sessenta anos antes de Borges, o escritor havia percebido que o realismo era, no fundo, "uma estética ruim", pois "toda arte é 'fazer' e é um mundo em si mesma de ilusão e formas simbólicas". ${ }^{62}$ É possível, creio, que a revolução formal do romance realizada por Machado de Assis depois de 1880 supere de maneira considerável o que Borges (que se concentrou na ficção curta, e não no romance) realizou com as ficções, e se Barth se tivesse concentrado nela nos anos entre 1956 e 1966, Machado, com sua profunda sabedoria, ${ }^{63}$ seu humor ácido, sua ironia lacerante, sua aguda consciência social e seu ceticismo irredutível, teria influenciado os escritores americanos no mínimo tanto quanto Borges, e talvez até mais. Na década de 1960, o país era uma cultura que ansiava por aquilo que Machado de Assis lhe teria podido dar, em termos artísticos e temáticos, mas não foi o que ocorreu. Estando frustrado, na época, como romancista neófito, tendo de resolver questões de tom e tema, ou seja, a questão de como escrever em um tom cômico sobre assuntos sérios, Barth ficou "sem fôlego" ao ler Machado, que lhe mostrou "como se tornar o romancista" que ele estava então tentando se tornar. ${ }^{64}$ Em 1966, no entanto, Barth já estava tornando-se um outro romancista, um escritor muito mais interessado em

\footnotetext{
${ }^{60} \mathrm{O}$ que ele não fez; ver: Further fridays: essays, lectures, and other nonfiction, 1984-94, cit., p. 166.

${ }^{61}$ HABERLY, David. T. Introdução. In: ASSIS, Machado de. Quincas Borba. Tradução de Gregory Rabassa. Oxford: Oxford University Press, 1998. p. xiii; xxiv; xxv-xxvi.

${ }^{62}$ WELLEK, René. The concept of Realism in literary scholarship. In: NICHOLS JR., Stephen G. (Org.). Concepts of criticism. New Haven: Yale University Press, 1963. p. 255.

${ }^{63}$ PUTNAM, Samuel. Marvelous journey: four centuries of Brazilian literature. Nova Iorque: Alfred A. Knopf, 1948. p. 178.

${ }^{64}$ BARTH, John. Further fridays: essays, lectures, and other nonfiction, 1984-94, cit., p. 166.
} 
questões de inovação formal e, como vemos em "A literatura da exaustão", fortemente seduzido pela revolução narrativa que Borges estava empreendendo. Talvez pelo fato de Barth, como tantos outros comentadores americanos, ter-se precipitado e lido Machado como uma espécie de imitador déclassé de Sterne, cujo Tristram Shandy ele julgava com segurança ser "sem dúvida uma realização mais brilhante do que qualquer das de Machado", ${ }^{65}$ não foi capaz de ver o brilho inovador do autor brasileiro, encontrando nos três romances que leu nesse momento apenas a solução para um problema específico que o impedia de completar o seu primeiro romance. Se, nos anos subsequentes, Barth tivesse refletido mais sobre como Machado estava repensando a natureza do gênero do romance (e não simplesmente escrevendo romances engraçados sobre assuntos sérios), ${ }^{66}$ seria bem provável que "A literatura da exaustão" tivesse tido um elenco mais brasileiro e, com isso, aumentado o interesse americano pela literatura brasileira.

Generalizações são sempre declarações perigosas e devem sempre ser recebidas com mais do que um grão de sal. E, no entanto, ao trabalhar com história literária e com as questões sempre escorregadias da influência e da recepção (e especialmente quando a cultura receptora não vê a cultura que a influencia como produtora de literatura digna de estima), elas podem nos ajudar a compreender o ambiente artístico e intelectual geral no qual se dá um caso específico de influência e recepção. Como busquei demonstrar, essa é uma questão de importância crucial para qualquer tentativa de se entender a natureza da recepção de Machado de Assis nos Estados Unidos dos anos 1950 e 1960. E, quanto ao Brasil atual, a mudança está no ar. O país já tem atrás de si mais de uma década de estabilidade política e de crescimento econômico constante e sustentado. E, se, como muitos acreditam, o Brasil se tornar um petro-state, seu impacto nas Américas e no mundo em geral será enormemente ampliado, e ele passará a ser uma força a ser levada em conta em diversas frentes. Cada vez mais, a literatura brasileira está sendo reconhecida como "a mais independente e talvez mais original literatura nacional do Novo Mundo", ${ }^{67}$ e seus maiores escritores,

\footnotetext{
${ }^{65}$ Idem, p. 44.

${ }^{66}$ Para Barth, a Ópera flutuante era uma "comédia niilista" (Further fridays: essays, lectures, and other nonfiction, 1984-94, cit., p. 259).

${ }^{67}$ ECHEVARRÍA, Roberto González; PUPO-WALKER, Enrique; HABERLY, David. Introduction to volume 3. In: ECHEVARRÍA, Roberto González; PUPO-WALKER, Enrique (Orgs.). The Cambridge History of Latin American Literature. v. 3. Cambridge: Cambridge University Press, 1996. p. 1.
} 
como Machado de Assis, estão finalmente obtendo o reconhecimento que lhes foi por tanto tempo negado. Com um progresso lento e constante, o Brasil parece pronto para finalmente libertar-se da dependência e da invisibilidade a que tão longamente foi relegado e que tornaram praticamente impossível realizar seu pleno potencial, assumir o seu lugar de direito no palco mundial e, mais pertinentemente às nossas preocupações, começar a ser levado a sério como uma cultura conhecida pelo rigor intelectual e pela criatividade artística. A propósito disso, como observa Roberto González Echevarría, professor de espanhol e literatura comparada em Yale:

Joaquim Maria Machado de Assis [...] é o principal escritor latinoamericano do século XIX e um dos melhores de todos os tempos. Se tivesse nascido na França ou na Inglaterra, não há dúvida de que suas obras ganhariam proeminência no cânone ocidental. No continente americano, ele certamente está no mesmo nível de Melville, Hawthorne e Poe. Nenhum escritor de língua espanhola se aproxima do seu refinamento e da sua originalidade $[\ldots]^{68}$

Echevarría declara que Machado é um "mestre das intrigas psicológicas sutis e dos dramas envolvendo as grandes questões que afligem a humanidade", e que ele "antecipa a tendência de Borges ao distanciamento irônico e ao autoapagamento do autor e a ela se equipara, mas seu ceticismo é menos corrosivo e mais compassivo". ${ }^{69}$ Embora Machado de Assis esteja finalmente começando a ganhar, nos Estados Unidos, o tipo de reconhecimento merecido (ver Sontag, ${ }^{70}$ Bloom, ${ }^{71}$ Dixon $^{72}$ e Rohter ${ }^{73}$ ), sua recepção nos anos 1950 e 1960 foi problemática por causa do momento em que foi publicado, por vir de uma tradição literária que não era amplamente respeitada (ou sequer conhecida) nos Estados Unidos e, mais tarde, nos anos 1960, por ter sido ignorado enquanto autor do

\footnotetext{
${ }^{68}$ Idem, p. 95.

${ }^{69}$ Ibidem.

${ }^{70}$ SONTAG, Susan. Afterlives: the case of Machado de Assis. New Yorker, 7 mai. 1990, p. 102-108.

${ }^{71}$ BLOOM, Harold. Joaquim Maria Machado de Assis, cit.

72 DIXON, Paul. Preliminary note. In: Santa Barbara Portuguese Studies, v. 8 (2004), número especial intitulado "Machado de Assis: the nation and the world"; DIXON, Paul, Guest Editor. Santa Barbara: Center for Portuguese Studies, the University of California, Santa Barbara, 2007. p. 9-11.

${ }^{73}$ ROHTER, Larry. After a century, a literary reputation finally blooms. New York Times, edição de Nova Iorque, 13 set. 2008 , p. B9.
} 
Boom por críticos isentos como John Updike e, em especial, como John Barth, cujo ensaio de 1967 "A literatura da exaustão" poderia ter feito por Machado o que fez por Borges. Mas Barth não é o problema aqui; o verdadeiro culpado é o "preconceito literário cego" ${ }^{74}$ que historicamente fez com que os americanos denegrissem a literatura latino-americana. É só agora, com a ascensão da literatura interamericana e com o recém-descoberto apreço por Machado de Assis por parte de críticos como Susan Sontag, Harold Bloom e Michael Wood, que a brilhante tradição literária do Brasil está finalmente recebendo o que lhe é devido. Embora tarde, a recepção adequada de Machado nos Estados Unidos finalmente está acontecendo.

Referências:

ARMSTRONG, Piers. Third world literary fortunes: Brazilian culture and its international reception. Lewisburg: Bucknell University Press, 1999.

BARTH, John. Further fridays: essays, lectures, and other nonfiction, 1984-94. Nova Iorque: Little, Brown and Company, 1995. p. 44-45; 165-167; 290.

The literature of exhaustion. In: The friday book. Nova Iorque: G. P. Putnam's Sons, 1984.

BLOOM, Harold. Joaquim Maria Machado de Assis. In: Gênio: os 100 autores mais criativos da história da literatura. Rio de Janeiro: Objetiva, 2003.

BRUSHWOOD, John. Two views of the Boom: North and South. Latin American Literary Review, Special issue: "The Boom in retrospect: a reconsideration". Yvette E. Miller and Raymond Leslie Williams, editors, v. 25, n. 29 (jan.-jun. 1987), p. 24.

COHN, Deborah. History and memory in the two souths: recent Southern and Spanish American fiction. Nashville: Vanderbilt University Press, 1999.

DIXON, Paul. Preliminary note. In: Santa Barbara Portuguese Studies, v. 8 (2004), número especial intitulado "Machado de Assis: the nation and the world"; DIXON, Paul, Guest Editor. Santa Barbara: Center for Portuguese Studies, the University of California, Santa Barbara, 2007.

\footnotetext{
${ }^{74}$ MONEGAL, Emir Rodríguez. The New Latin American Literature in the U.S.A., cit., p. 4.
} 
DONOSO, José; HENKIN, William (Orgs.). The TriQuarterly anthology of contemporary Latin American literature. Nova Iorque: E. P. Dutton, 1969.

ECHEVARRÍA, Roberto González; PUPO-WALKER, Enrique; HABERLY, David. Introduction to volume 3. In: ECHEVARRÍA, Roberto González; PUPO-WALKER, Enrique (Orgs.). The Cambridge History of Latin American Literature. v. 3. Cambridge: Cambridge University Press, 1996.

FITTS, Dudley. A masterpiece from Brazil. New York Times, 13 jul. 1952, p. 4. Legacy from Brazil. New Republic 131, 20 set. 1954, p. 19.

FITZGERALD, S. M. A belated discovery. New Republic, 15 set. 1952, p. 20.

GROSSMAN, William L. Victory and potatoes. Saturday Review 37, 17 jul. 1954, p. 12.

HABERLY, David. T. Introdução. In: ASSIS, Machado de. Quincas Borba. Tradução de Gregory Rabassa. Oxford: Oxford University Press, 1998. p. xiii; xxiv; xxv-xxvi.

JACKSON, K. David. Madness in a tropical manner. The New York Times Book Review, 22 fev. 1998, Nova Iorque, p. 15.

KAZIN, Alfred. On native grounds: an interpretation of modern American prose literature. Nova Iorque: Reynal \& Hitchcock, 1942.

KOCH, Stephen. Premature speculations on the perpetual Renaissance. TriQuarterly Review, 10. Fall 1967, p. 4-19.

KOSTELANETZ, Richard (Org.). On contemporary literature. Expanded edition. Nova Iorque: Avon, 1969.

MCCLENNEN, Sophia A. Comparative Literature and Latin American Studies: from disarticulation to dialogue. In: MCCLENNEN, Sophia A.; FITZ, Earl E. (Orgs.). Comparative Cultural Studies and Latin America. West Lafayette: Purdue University Press, 2004.

MCQUADE, Donald; ATWAN, Robert; BANTA, Martha; KAPLAN, Justin; MINTER, David; TICHI, Cecilia; VENDLER, Helen (Orgs.). The Harper American Literature. v. 2. Nova Iorque: Harper and Row, 1987.

MERQUIOR, José Guilherme. The Brazilian and Spanish American literary traditions: a contrastive view. In: GONZÁLEZ, Roberto González; PUPO-WALKER, Enrique (Orgs.). The Cambridge History of Latin American Literature. v. 3. Cambridge: Cambridge University Press, 1996. 
MONEGAL, Emir Rodríguez. El Boom de la novela latinoamericana. Caracas: Editorial Tiempo Nuevo, 1972.

MONEGAL, Emir Rodríguez. The new Latin American Literature in the USA. Review 68. Nova Iorque: The Center for Inter-American Relations, 1968, p. 3.

NUNES, Maria Luísa. The craft of an absolute winner: characterization and narratology in the novels of Machado de Assis. Westport, CT: Greenwood Press, 1983.

Partisan Review. PHILLIPS, William; RAHV, Philip (Orgs.). Our country and our culture: a symposium. v. 19, n. 3 (mai.-jun. 1952.), p. 282.

PAYNE, Johnny. Conquest of the New Word: experimental fiction and translation in the Americas. Austin: The University of Texas Press, 1993.

PUTNAM, Samuel. Marvelous journey: four centuries of Brazilian literature. Nova Iorque: Alfred A. Knopf, 1948.

ROHTER, Larry. After a century, a literary reputation finally blooms. New York Times, edição de Nova Iorque, 13 set. 2008, p. B9.

ROSTAGNO, Irene. Searching for recognition: the promotion of Latin American literature in the United States. Westport, CT: Greenwood Press, 1997.

ROTH, Philip. Writing American fiction. In: KLEIN, Marcus (Org.). The American novel since World War II. Nova Iorque: Fawcett, 1969.

SONTAG, Susan. Afterlives: the case of Machado de Assis. New Yorker, 7 mai. 1990, p. 102-108.

STERN, James. Illusion of grandeur. New York Times Book Review, 18 jul. 1954, p. 19.

UPDIKE, John. The author as librarian. The New Yorker, 30 out. 1965, p. 223-246.

VIDAL, Gore. Ladders to Heaven. In: KOSTELANETZ, Richard (Org.). On contemporary literature. Expanded edition. Nova Iorque: Avon, 1969.

WEBSTER, Harvey Curtis. A short life is not bitter... Saturday Review 35, 26 jul. 1952, p. 9.

WELLEK, René. The concept of Realism in literary scholarship. In: NICHOLS JR., Stephen G. (Org.). Concepts of criticism. New Haven: Yale University Press, 1963.

WEST, Anthony. A minor classic. New Yorker, 9 ago. 1952, p. 71.

WILKIE, Brian; HURT, James (Orgs.). Literature of the Western World. v. 2. Nova Iorque: Macmillan Publishing Company, 1984. 
Earl Fitz é professor de português, espanhol e literatura comparada na Vanderbilt University, em Nashville, Tennessee, nos Estados Unidos. É autor de Rediscovering the New World: Inter-American Literature in a Comparative Context (1991), Brazilian Narrative Traditions in a Comparative Context (2005), e, em parceria com Judith Payne, Ambiguity and Gender in the New Novel of Brazil and Spanish America: A Comparative Assessment (1993). Em parceria com Elizabeth Lowe, tambem publicou Translation and the Rise of Inter-American Literature (2007). Atualmente, dá aulas na Vanderbilt University de literaturas brasileira e hispano-americana, estas duas tradições em comparação, e de literatura interamericana. E-mail: <earl.e.fitz@ vanderbilt.edu> 